\title{
TASK XVII
}

REVIEW OF THE CS STRATEgy HAlll

DOCUMENT AND MAKE RECOMMENDATIONS

\section{TO THE STAFF OF CPP}

\author{
Submitted To: \\ Department of Energy \\ Contract No: EM-78-C-01-4249
}

\section{Prepared By:}

\begin{abstract}
Donovan, Hamester \& Rattien, Inc. 1055 Thomas Jefferson Street, NW Suite 414

washington, D.C. 20007
\end{abstract}

DOE/CS/20059--T14

DE82 013311

June 30,1980

\section{$\mathrm{dh} r_{\text {donovan, hamester \& rattien, inc. }}$}




\section{DISCLAIMER}

This report was prepared as an account of work sponsored by an agency of the United States Government. Neither the United States Government nor any agency Thereof, nor any of their employees, makes any warranty, express or implied, or assumes any legal liability or responsibility for the accuracy, completeness, or usefulness of any information, apparatus, product, or process disclosed, or represents that its use would not infringe privately owned rights. Reference herein to any specific commercial product, process, or service by trade name, trademark, manufacturer, or otherwise does not necessarily constitute or imply its endorsement, recommendation, or favoring by the United States Government or any agency thereof. The views and opinions of authors expressed herein do not necessarily state or reflect those of the United States Government or any agency thereof. 


\section{DISCLAIMER}

Portions of this document may be illegible in electronic image products. Images are produced from the best available original document. 


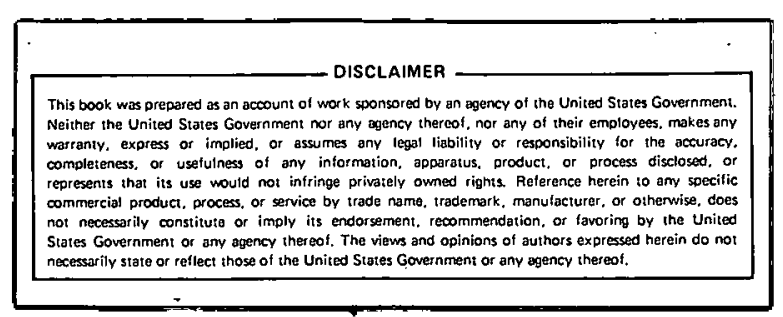

\section{Strategy Background Paper Critique: The Building Sector}

\subsection{Background}

- General remarks: The comments here are primarily intended to help tighten the organization of this section.

- Page 1:

- The data on residential and non-residential stock should be preceded by a definition of the Buildings sector (e.g.," "The Buildings Sector consists of the Residential and Commercial sectors. There are now about ...") .

- More recent data on energy use are available: Residential and Commercial Sectors consumed 29.28 quads, or $37.5 \%$ of total energy use in 1979 (Monthly Energy Review, 2/80).

- ORNL figures for consumption by sector, fuel type and end use may be engineering extrapolations rather than actual data. (see Table 1-1 for 1979 consumption by fuel type.)

- The reference to conservation targets is unclear. The figure of $81 \%$ seems to refer to the big targets but is followed by a list that includes all end use sectors ("space heating and air conditioning, water heating and lighting as well as cooking, refrigeration, and others"). 
- Page 2 (Pie Charts): The differences between the ORNL and EIA estimates are fairly large (see previous comment on ORNL figures).

- Page 3:

- It is important to include data from 1975 to 1979 here (see Table 1-1) to indicate trends in the late '70's.

- It is also important to note that the increases in energy use are due to:

1) Increased stock of residential and commercial units; e.g.,

$$
\text { Housing Units }\left(10^{6}\right)
$$

1960 $\underline{1970}$ 1976 74

2) Increased energy use per unit, this factor largely resulting from energy prices that generally declined in real terms from $1950-1973$ (e.g., crude oil wellhead prices, in constant 1972 dollars, declined from $\$ 4.89 / \mathrm{bbl}$ in 1948 to $\$ 3.39 / \mathrm{bbl}$ in 1972 , a $31 \%$ decrease; the price of natural gas to residential consumers, in 1972 dollars, rose from $\$ 1.229 / \mathrm{MCf}$ in 1948 to $\$ 1.506 / \mathrm{MCf}$ in 1960 and subsequently fell to a low of $\$ 1.193 /$ Mcf in 1970). 


\section{Table $1-1$}

Energy Consumption by Fuel Type in the Residential and Commercial Sectors

Fuel Type (quadrillian Btu)

$\begin{array}{llllll}\text { Year } & \text { Coal } & \begin{array}{c}\text { Natural } \\ \text { Gas }\end{array} & \text { Petroleum } & \begin{array}{c}\text { Electricity } \\ \text { (Primary) }\end{array} & \text { Total } \\ 1973 & .293 & 7.626 & 6.831 & 11.784 & 26.534 \\ 1974 & .292 & 7.518 & 6.214 & 11.888 & 25.912 \\ 1975 & .248 & 7.581 & 5.839 & 12.313 & 25.981 \\ 1976 & .239 & 7.866 & 6.290 & 12.785 & 27.180 \\ 1977 & .234 & 7.462 & 6.327 & 13.521 & 27.545 \\ 1978 & .265 & 7.679 & 6.423 & 14.195 & 28.563 \\ 1979 & .242 & 7.991 & 6.663 & 14.384 & 29.280\end{array}$

Source: Monthly Energy Review, February 1980 
- Page 5:

- See comments immediately above. The increases in energy use should not be attributed solely to declining energy prices but to the combination of increased stock plus declining prices.

- Discussion of stocks of appliances should be with the discussion of stocks of housing units, with both preceding the discussion of prices.

- The discussions of capital stock lifetimes and solar potential would be more appropriate in Section II, Potential for Conservation and Solar.

\subsection{Potential for Conservation and Solar}

- General comments: This section șhould distinguish technically feasible from cost-effective investments. It should also point out that the rate at which cost-effective conservation and solar investments can be made depends upon:

1) Rate of capital stock turnover; and,

2) Price paths of oil, gas, etc.

- Page 10:

- This section should begin with discussion of technically feasible conservation and solar. Figure 4 could be referenced and discussed here. The maximum technical potential for conservation as identified in the APS study should also be referenced and discussed. 
- Following the first paragraph on page 10

(i.e., the discussion of technical potential)

there should be a discussion of economic

feasibility. This could be as follows:

Not all of the technically feasible energy conservation and solar energy measures are cost-effective at present. However, increasing numbers of these investments have become cost-effective as a result of price increases in oil, gas and electricity during the $1970^{\prime} \mathrm{s}$. One analysis reports that costeffective conservation measures that could have been implemented between 1973 and 1978 would have led to a $33 \%$ reduction in the actual 1978 energy use in buildings* (see Figure 2-1).

The efficiency improvements actually made during this time period resulted in only a 28 savings over what would have been the case had no improvements been made. Had all short-term cost-effective improvements been made, consumer expenditures for energy used in buildings in 1978 would have been $23 \circ$ less than actually occurred. Thus, there is a significant potential for energy use reduction that is not only technically feasible but is also quite cost-effective.

An obvious question that arises is: why hasn't the conservation potential in the buildings sector been fully exploited if conservation investments are so cost-effective? The answer is that numerous institutional and policy barriers as well as market imperfections continue to distant market signals and inhibit consumer responses to rising energy prices. While these barriers are more completely discussed in Section III, it is important to note here that federal programs are designed to remove these barriers so as to encourage timely achievement of the full conservation potential.

* Sant, R.W., The Least-Cost Energy Strategy. The Energy Productivity Center, Mellon Institute, Arlington, Virginia (Carnegie-Melion University Press, 1979). 


\section{FIGURE $2-1$}

\section{BUILDINGS ENERGY SERVICE MARKET SHARES(1) OF VARIOUS TECHNOLOGIES}

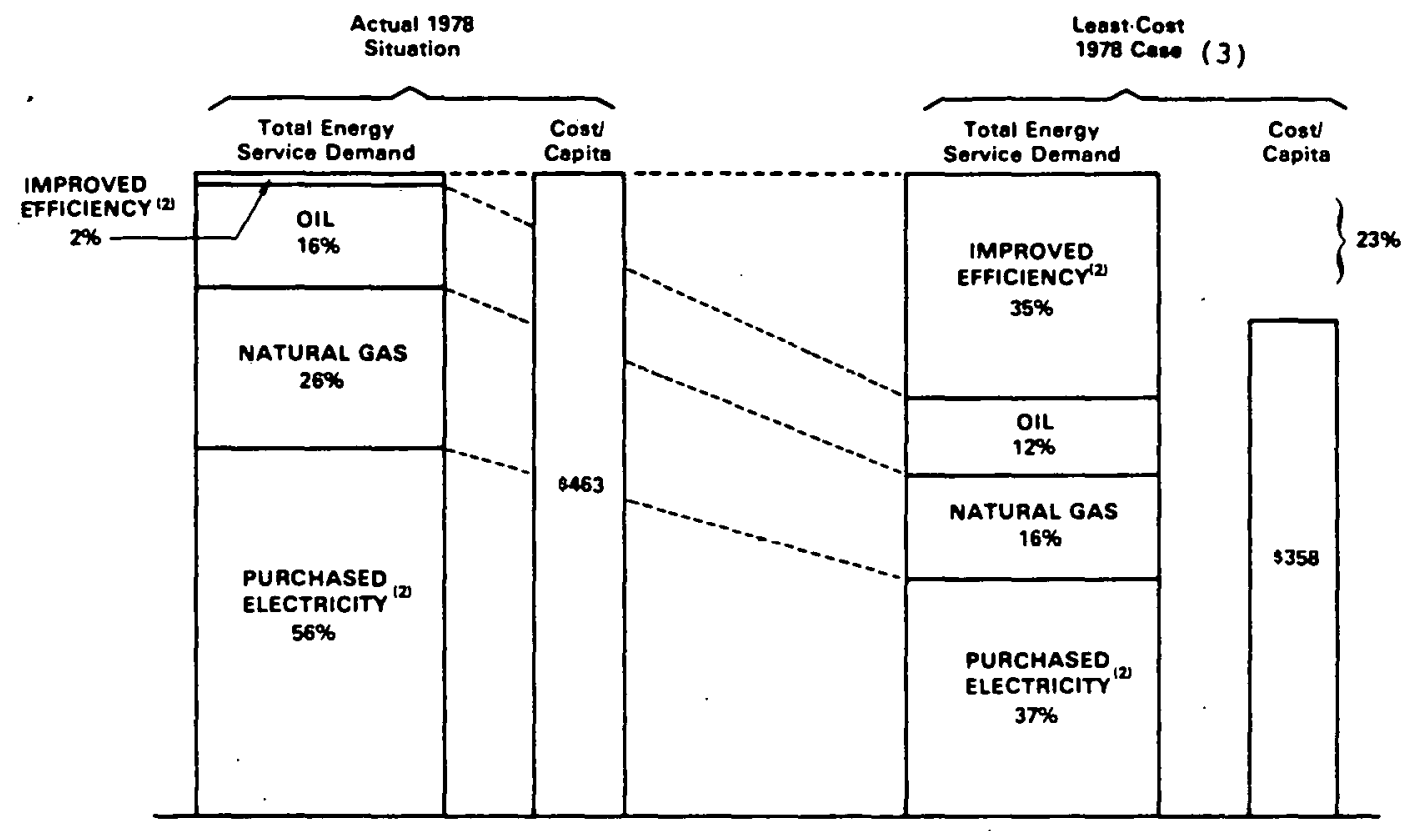

(1) THE PaIMARY FUEL EQUIVALENT OF SERVICE DEMANO WAS 29.3 QUADS. PLUS 0.7 QUADS. OF IMPROVED EFFICIENCY (CALCULATED AGAINST A 1973 BASEI. OR A TOTAL OF 30.0 QUADS

(2) IN TERMS OF PRIMARY FUEL.

(3) The analysis used the Buildings Energy

Conservation Optimization Model (BECOM)

and assumed renovation but no replacement of buildings.

Source: Sant, R.W. op cit. 
The conservation potential will increase

in future years as:

1) Existing capital stock can be replaced by more energy-efficient capital stock.

2) Energy prices continue to rise, thus making more solar and conservation investments cost-effective.

- At this point, a discussion of capital stock turnover rates and energy price projections would be appropriate. This would be followed by the discussion of the CONAES projections.

\subsection{Barriers to Conservation and Solar Energy}

- General comments: This section should more clearly state why each barrier is a barrier to cost-effective conservation and solar investments. As it is now written, it is not clear that these are barriers to investments that should be made. For example, barriers such as unreliability of solar systems and poor installation leave the impression that the solar industry is not yet ready to market its products. This section, though, should make the opposite point: solar is technically feasible and many conservation and solar investments are cost-effective but market imperfections and institutional barriers are retarding consumer investments in conservation and solar. 
There should also be discussion of which barriers are the most significant. This discussion could particularly focus on the importance of supplyrelated barriers relative to demand-related barriers.

The distinction between Economic Barriers and Consumer Demand Barriers may not be useful because so many of the Consumer Demand Barriers pertain to economic and financial constraints. The following categories might be more useful:

(1) Technological Barriers

(2) Market Imperfections

(3) Institutional and Regulatory Barriers

- Page 14:

- The initial sentence should be, "Energy conservation is progressing more rapidly in the Industrial and Transportation Sectors than in the Residential/Commercial sector" (see Table 3-1). This table indicates that energy use demand in the Residential/ Commercial sector is decreasing less rapidly than in the other sectors. Additional references could be made to industrial progress under the voluntary energy efficiency guidelines. 
Table 3-1

Energy Use by Sector

(Quadrillion Btu)

Total Sectors Industrial transportation $\begin{gathered}\text { Residential and } \\ \text { Commercial }\end{gathered}$

$\begin{array}{lllll}1973 & 74.605 & 29.144 & 18.927 & 26.534 \\ 1974 & 72.756 & 28.430 & 18.414 & 25.912 \\ 1975 & 70.706 & 26.207 & 18.518 & 25.981 \\ 1976 & 74.513 & 27.924 & 19.408 & 27.180 \\ 1977 & 76.536 & 28.923 & 20.068 & 27.545 \\ 1978 & 78.442 & 29.266 & 20.614 & 28.563 \\ 1979 & 78.186 & 29.146 & 19.760 & 29.280\end{array}$

Source: Monthly Energy Review February 1980 
- This should be followed by a brief explanation to the effect that energy use consumption in the Residential/Commercial sector is higher than the economically efficient level because numerous institutional and policy barriers as well as market imperfections continue to distort market signals and inhibit consumer responses to rising energy prices.

- The discussion of characteristics of the buildings industry in the first paragraph should be placed under Institutional Barriers.

- Technological barriers should be defined (e.g., "Some conservation and solar investments are either technically infeasible or too costly"). It is important to note that this applies only to some conservation and solar technologies; many are quite cost-effective, but have been inhibited by e.g., institutional barriers. It would be helpful to include a table that indicates which generic solar and conservation technologies are: (a) in R\&D phase; or, (b) commercially avallable.

- Points (1) and (2) on the buildings industry should be placed under institutional barriers.

- Page 15:

- Point (1) on this page depicts the solar industry as providing uniformly poor products and service. 
The point should be that some technologies are not yet ready and require further development; consumer perceptions of solar technologies should be discussed "Market Imperfections".

- Point (2) con investment in production of new products) should be placed under "Market Imperfections". The argument is that producing new products for an uncertain market is a risky business. Since individual firms are more riskaverse than the federal government (which represents the public), there is too little investment in producing new solar and conservation equipment. However, this argument appears weak: demand-related constrants are probably more significant.

- "Economic and Financial Barriers" could be retitled, "Market Imperfections" and expanded to include those barriers now listed under "Consumer Demand Darriers".

- The following barriers under "Market Imperfections" * are probably most significant:

1) Consumers do not face true replacement cost prices for energy:

(a) Artificially low prices have resulted from regulation;

(b) Externalities have not been incorporated into the prices of conventional fuels.

* Includes those now listed under "Economic and Financial Barriers" and "Consumer Demand Barriers." 
2) First-cost bias among consumers.

3) Risk aversion/uncertainty:

(a) Consumers are generally reluctant to invest in technologies perceived to be new, unproven or risky;

(b) Consumers are not yet certain that they can capture the value of solar/conservation investments in resale.

4) Neither landlords nor tenants have sufficient incentive to invest in conservation/solar for rental property.

5) Information on conservation/solar investments has been unavailable, inadequate, or too time-consuming to obtain.

6) Many consumers, particularly those with fixed or low incomes, have limited access to financing.

- The discussion should explain why the barriers above constitute market imperfections that must be rectified in order to permit a timely shift to solar and conservation.

- Pages 16-17: Institutional and Regulatory Barriers

- Fragmentation of the construction industry belongs under "Institutional Barriers."

- Several points pertain to building codes and zoning restrictions; the organization of this section would be 
clearer if those various points were grouped together under "Building Codes and zoning Restrictions."

- The point that communities have not demonstrated

a sense of urgency in launching conservation campaigns is accurate but requires some elaboration. What are the actual barriers that have inhibited communities from acting? Do they involve lack of information as to what can be done on a community level? Or are there other problems?

- Page 18:

- Point (1) on this page suggests that the public is justifiably reluctant to accept solar energy systems because the industry is incapable of providing good service. This is statement is too sweeping. The point should be part of a discussion of "Solar Energy Industry Readiness" and there should be some assessment as to whether the industry's readiness actually constitutes a barrier.

- With respect to utilities, there should be a short statement on the extent to which utility-related barriers (e.g., declining-block rate structures, absence of peakpricing) are now disappearing due to utility actions, public utility commissions' actions, etc. There should be an asssessment that indicates whether utility related barriers that were important five years ago will continue to persist. 


\subsection{The Government Role in The Buildings Sector}

- General comments: This section would be much clearer if it was keyed to the barriers identified in the previous section. Each action should also be designated as appropriate for Federal, State, or local government. For example, the government plays an important role in regulating utilities. This is primarily a state role. In addition, there is a Federal role that involves encouraging State Public Utility Commissions to begin setting rates based upon marginal costs and eliminate declining-block rate structures. A figure such as Table I-3 of the Draft Conservation Strategy dated November 26, 1979 (reproduced on following page) might be helpful in keying policies to barriers.

- Page 21:

- The references on this page to the "controlled or regulated fuel market" are too sweeping: they seem to indicate that regulation of energy prices is the only barrier to coneervation/solar.

- The explanation of the general role of the Federal government is not as clear as it could be. Bulletizing or itemizing the three classes of Federal action would help clarify this paragraph.

- Pages $22-23$ :

- These actions should be keyed to the barriers identified in the previous section. 
Table 1-3. Summary of Barrfers to Conservation and Impacts of Government

Policies and Programs on Overcoming Barriers

\section{DARRIERS TO CONSERVATION}

011 and cas Prices Controlled at Below Replacement Costs

- Large sunk costs. In ineffictent capital stocks

- Lag in adjustments to real cost of. energy

\section{Imostinent Criteria}

- Emphasis on reducing intelal investment and not life cycle costs

- Desire for short payback perfods on imestinents

\section{Lack of Adequate Information}

On equipwent costs, performance/ benefits, tax credits, benefits and methods of wore effictent use

\section{Private Sector RaD}

- Project technical risks

- Project marketability risks due to fuel price uncertainty

- Limited R8D resources

- Capturing the beneftts of RBD

\section{Legay/Institutional Barriers}

- Buflding codes

- Decilning block rates for electricity

- Restrictions on role of electricity from cogeneration

\section{GOVERNMENT POLICY AND PROGRAM OPTIONS}

Graduated Price Decontrol

Affects Iffe cycle costs and payback perlods for advanced conservation and solar technologies

Affects economics of more efficient energy usage patterns

Information/Demonstration/Commercialization Programs

Improve confidence in equipment costs and performance

Make people aware of ife cycle costs, payback perfods, impact of tax credits

Make people aware of benefits of more efficient usage

Government Sponsored R8D

Spreads or reduces technical risks

Supplements 1 imited R\&O resources

Reduced equipment investment cost/increased performance due to R\&D improves life cycle costs and payback periods

\section{Economic Incentives}

Reduce investment cost and improve life cycle costs and payback periods

\section{Standards and Regulattons}

Force project development in some Instances

Force market penetration

Force more energy-effictent behavior

Federal Atd and Intervention in State and Local Jurisdictions

Ensures participation of wil levels of government 
- Some of these points belong in Section V: Current Federal Policies, Programs and Impacts (e.g., "Reduce energy use by $20 \%$ in existing Federal bruildings by 1985...") because they pertain primarily to specific programs and program impacts. This section ought to focus on identifying the types of government actions that are appropriate and should explain why these types of actions complement private sector efforts.

- Pages 23-28:

- The pages that identify program missions and goals for BCS, Solar Buildings and the State and Local Programs seem more appropriate for section $v$.

- The section on page 28 entitled "The Role of State and Local Governments" should immediately follow the section on the Federal role.

\subsection{Current Federal Policies, Programs and Impacts}

- General comments: The description of the current conservation program could be supplemented with a chart in which each of the programs is identified, program elements are listed and major objectives are briefly characterized. For both the conservation and solar programs, there should be more discussion relating these programs to the barriers that were identified in section III. In addition, the eneryy savings under current programs should be compared to the energy savings potential identified in section II. 


\subsection{Alternative Federal Initiatives}

- General comments: This section should begin with an expanded discussion of the gap between energy savings under current programs and potential energy savings. The reader must be convinced that, while current programs are very cost-effective and will result in significant energy savings, additional efforts are needed in order to help achieve the full conservation potential. The new initiatives should also be keyed to the barriers previously identified.

- Page 44-49:

- Some of the proposals are not appropriate DOE actions and others are not appropriate for Federal action, e.g.:

(1) Revising charter of the Federal Home Mortgage Insurance Corp. (p 47);

(2) Moving away from declining block rates for utilities (p 47 );

(3) Simplify building codes: zoning restrictions and tax laws (p 48);

(4) Update municipal building codes (p 48);

(5) Allow homeowners flexibility in complying with building codes (p 48);

(6) Address solar access rights ( $p$ 48). 


\section{Strategy Background Paper Critique:}

Transportation

The transportation sector background paper presents an abundance of facts and information, and promises to almost double the amount with later insertions. In general, the information sums to be of good quality and almost all the material presented therein will be useful to the strategy process. There are, however, certain improvements that can be made, particularly in: 1) comprehensiveness of the information provided for the strategy; 2) presentation of the material in a form that is useful to the strategy process:

One general comment should be made. Although these are only background papers, and a final analytic effort will yield the strategy document chapters, these papers should provide the reader with a clear indication of why the facts included are relevant and useful. This background paper should be reviewed for precisely this quality. For example, why should we be interested in scrappage rates?; are scrappage rates of equal importance in each transportation mode or does their significance vary? These kinds of questions are not answered. It is understood that the time constraint was a limiting factor but the sections do not now form a coherent whole. Further work should be directed at correcting this problem even if it is at the expense of completing some of the tables promised, etc. 
Section-by-Section Comments

Summary

"The current Government strategy."... This paragraph does not present a "strategy" but, rather a list of federal tools. The terms "strategy" should be used sparingly and with caution.

Figure 1: similarly "strategy" should be replaced by tools or mechanisms

See Table I-l for additions

Background

There is a need for a short but clear discussion of this sector's significance in terms of national energy consumption and, in particular, petroleum consumption. Also discuss why "highway modes" and "non-highway modes" are significant categories.

Define "\% of passenger transportation". Is it in terms of passenger miles? Same for freight.

Describe why a unit of measure like passenger-mile is the most useful concept, and how passenger miles relate to fuel consumption (i.e. the connection made by fuel use $(p-m)$.

\section{A. I Autos}

Do we have any info on what effect population growth is expected to have and what demographic projections suggest about future auto use?

Explain why scrappage rates are relevant. Recapitulate what the table shows or relable.Energy efficiency and tull consumption of autos should appear in more than just a table. The executive summary contains material that is not in the text.

Btu's per passenger-mile and/or passenger-miles per gallon should be discussed. 
A. 2

Define "modal share"

State why the propulsion technology used is of interest when discussing energy conservation.

Discuss why age and scrappage rates are important

Why is there no fuel use per-truck-mile or freight miles given?

A. 3

1972 data given -- is there anything more recent? For example Greyhound claims to have gotten 140 passengermiles per gallon in 1978 .

A. 4

This mode is included as if it is just as important as the others. The discussion should show why it is or is not.

B. 1

Non-Highway modes

Brief description of what are the non-highway modes.

It is preferrable to describe market share in terms other than "modal share".

Explain connection between low maintenance and loss of competitiveness.

What to the scrappage numbers tell us?

B. 2

Define general aviation as opposed to domestic civil aviation.

Which commodities are flown?

What are Btus per passenger-mile?

Define "stage length".

B. 3

"(41.5\% of domestic commerce in 1974)"??

Pipelines are discussed under marine transport. Is this a mistake? 
General Comments

In this whole sub-section there is no indication

of how significant these modes are in terms of consumption.

There is no mention of mass-transit. It should be added.

II. Potential

Table II-2 see note.

It would be illuminating to state potential savings

in terms of both percent of total consumption and percentage of model consumption.

D.

Methanol'slong term potential: text suggests that vehicle engines will be adapted for methanol. Why is this true? What indicates that this will happen?

Why do numbers in the text following Table II-7 not match the numbers in the table?

III. Barriers

C. Legal and Institutional

The first paragraph lists very broad barriers without giving indication of how they apply to transportation or how significant they are.

Clarify discussion of regulated vs non-regulated modes.

Add discussion of recent changes relating to highway trust fund.

E. "The long-lead time..." can we say anything more about how these apply to transportation?

A page is missing.

IV. Government Role

No mention of price decontrol.

No mention of regulatory role and its justification. 
V. State and Local

Good discussion.

VI. Federal policies and Programs

A1.3. Alternative Fuels

More info needed on federal approach to biomass.

How does it relate to goals and potential?

A. 2 Other DOE policies

Synfuels? Coal? Tar Sands? Shale?

VII. New Federal Initiatives

Alternative fuels, etc.:

More R\&D into lighter, more durable alternatives to lead-acid batteries.

Increased dieselization, including $R \& D$ to overcome potential environmental and health problems

Assistance to regions, states and communities:

Subsidies to public transport systems.

Regulation:

Requirement that gas stations provide functioning, easy-to use tire-checking equipment

Tax :

Special tax on recreational vehicles. 


\section{Stragegy Background Paper Critique: Public Utilities Sector}

In its present form the chapter entitled "Conservation and Solar in the Public Utilities Sector" is only partially complete, and thus cannot receive a comprehensive evaluation. However, even with the present material there are several areas that need attention. First and foremost the present chapter lacks coherence and thematic unity. The coherence can be provided by an overview section which sets forward the different opportunities present in the utility sector to conserve energy. There is an attempt to provide such an overview in section 2.2 . Described here are the two supply-side conservation techniques for utilities, i.e. management control and innovative technology improvements to improve efficiency of production processes. However, this is not enough.

The overview must take a broader perspective by first noting that the utilities are important in two kinds of conservation: 1) supply-side conservation where the utility actually increases its operating efficiency, and 2) demand-side conservation where the utility through various, methods encourages conservation in its customers. In each of these categories there are subcategories which describe the conservation opportunities for utilities more precisely. For supply-side conservation there are at least two areas: 1) utility power production management, and 2) introduction of more efficient technology both in generation (or energy conversion) and distribution. Examples of 
such technology introduction are utility applications of large WECS, solar thermal repowering, cogeneration, magnetohydrodynamics, etc.

For demand-side conservation there are three areas:

1) conservation technology for the utility customer (e.g. insulation, energy efficient appliances); 2) alternative energy technology for the customer (e.g. active solar), and 3) loadleveling strategies. These are the areas where the utilities can play the operative role and determine the success or failure of energy conservation initiatives.

Consequently, with these two general breakdowns in supplyside and demand-side opportunities, the types of initiatives needed on the part of the government should be designed to encourage more efficient power production, and greater contact between the utility and its customer in order to modify demand.

In addition to this overview, the chapter should note that virtually all the C\&S programs will affect a utility's demand profile. Obviously, all the building conservation programs, active and passive solar programs, wind energy and photovoltaic programs, etc. will impact the utilities. However, this is relatively unimportant in the context of a strategy to use the utilities themselves as tools to effect energy conservation. For this chapter one is more interested in the opportunities of actively engaging the utilities in energy conservation activities, not how utilities are affected incidentally by other conservation initiatives. Th1s type of insight into the rationale of 
the c\&s effort in the utility sector must be supplied in an initial section with the other material reorganized accordingly.

In order to provide an overview, historical data, such as that presented in Section 1.0, should be presented. However, numerous data tables are by themselves not informative. Some explanatory text is needed to provide the appropriate insights and highlight the important points found in the data. These explanations should relate the data to the utilities' importance as agents for promoting energy conservation. Furthermore, the figures and tables themselves should be edited to eliminate some of the less important ones.

Other general comments as to how the chapter can be improved include:

- Instead of scattering the discussion of relevant Federal utility legislation, there needs to be a comprehensive and systematic presentation of all legislation, possibly in an appendix.

- Section 3.0 on barriers to energy conservation is very important. However, the present version should be rewritten to provide an adequate overview of the problems.

- In Section 5.0 there is a brief description of the RCE program. Yet, the RCS program is a major initiative to use the utilities to encourage energy conservation among its customers. This interaction, i.e. between the utility and its customers, is exactly the kind of 
of interaction which must be developed. Consequently, the RCS program needs further treatment in the text.

- Finally, the entire chapter needs a close editing job to generally streamline the chapter. For instance, tables, figures and sections need consequetive enumeration; in many instances footnotes are indicated, but not provided; all tables and graphs need references; any table referenced in the text should be listed; etc. In addition to these general comments some specific comments concerning the text and the tables are listed below.

Fiqure 1.4 - On the graph, the residential, commercial, and industrial components do not drop in '76, so why does the total?

Table 1.9 and 1.10 - These are reprinted from the RNL/DJA modeling work for OPPE, but the estimates have since been revised. The tables need a reference.

Section 1.2.1 (3rd paragraph) - Pure competition by definition precludes collusion of competitors. Rather in a "non-regulated" supply market, competitors can collude to inflate prices.

Section 1.2.2 - Does the ICC have any authority with utilities?

Section 2.2.1 (5th paragraph) - Management has responsibility in more than two areas for preventing efficiency losses. What about maintenance, fuel acquisition, etc.? 
Table 2.1 and 2.2 - Do these numbers reflect only the fuel displaced in utility applications.

Section 3.1 (paragraph 5) - It is difficult to make such

a general statement about utilities, since there is substantial diversity within the utility sector. Some consider themselves more than just providers of electricity and gas. Section 5.1.1.1.a - The energy storage program when applied to utilities will level the supply curve of solar component in a utility's supply mix. The storage program applied to customers will level demand, but then it is not a utility program. 


\section{Strategy Background Paper Critique: The Industrial Sector}

The paper sets out to investigate a number of policy considerations in the area of industrial use of conservation and solar energy, and to provide a logical framework for considering the policy issues. It should be stated at the outset that it fulfills these functions reasonably well and much of the analysis is presented in an attractive and readable manner.

The major criticism one would make is that the stated purposes are only part of what a background paper for the Conservation and Solar Strategy Document should encompass. There is, for example, no adequate statement of existing programs and what they are trying to do. The list that is presented is too concise and gives the reader no clear idea of the goals of the programs, much less whether progress towards these goals is being made ad an acceptable rate. Similarly, the series of questions at the end of the paper is hardly a comprehensive discussion of the policy issues. However, it should be borne in mind that a fuller treatment of programs and policies would probably double (at least) the length of the paper.

There is also no analysis of the potential for energy savings with existing technology (a 1974 Ford Foundation study estimated that consumption in the six major energy-using industries could be reduced by one-third) nor of the contribution that new 
technologies might make. The barriers to conservation and solar in industry are addressed only haphazardly in the context of other issues rather than systematically.

To turn to more detailed points, the section dealing with historical patterns of sectoral energy use is straightforward and highlights a number of important developments very well. However, it is not always clear in the text what measure of energy consumption is being used: Within two paragraphs on pp. $4-5$, there is reference to energy use "per value of output" (dollar value?), "per unit output", and "per product". While it is pointed out that energy use per unit of output has declined overall since 1972, there is no discussion of why this might have occurred. Moreover, in the sections dealing with consumption by the industrial subsectors, the data presented ends in 1974 which is regrettable, since developments since 1974 are of particular interest. One table, the ranking of construction industry sectors by energy intensities; is from 1967.

The discussion of the levels of decision-making in energy use is interesting, but is sometimes more opaque than other sections of the paper. For example, the meaning of the following paragraph. (p.36) is not at all clear.

"The remaining level of choice of process technology is economy wide. The important elements here are the fundamental aspects of production which, to a greater or lesser extent, dictate the choice of process technology utilized. Conversely, they 
are the fundamental aspects of production which mitigate against the use of given production processes."

Nor is it always clear what the distinction is between "process choice" and "output choice", particularly at the economy-wide level, nor why investment decisions should be linked only to the latter. There are some odd statements, e.g., "there is a strong presumption that the state of the economy is not independent of energy usage" - there is surely a stronger presumption of the opposite relationship.

The section headed "Market Specific Process Choice" includes a discussion of promising technologies, and some of the barriers to their adoption are mentioned, but they are not analysed in detail. The issue of whether an economic analysis is more important than a purely energy-oriented analysis is also raised. But there is no obvious reason why this section should occur at this point in the paper - it would more appropriately belong in a fuller discussion of the impact of DOE programs and the barriers facing them.

In the section "Firm Specific Process Choice," mention is made of the relationship between the diffusion of technology and the structure of industry, with the implication that the degree of concentration affects the rate of innovation. In general, most studies of the relationship between industrial concentration and the role of technological change seem to conclude that a slight amount of concentration may promote more rapid invention and innovation, 
and since the major energy using industries are not considered especially concentrated, the concern of the paper does not appear especially relevant.

The description of Federal Policies mentions some justifications for a government role in conservation, but fails to cover such issues as improved energy-efficiency in products as a contribution towards helping the US balance of payments; nor the legal, institutional, and regulatory questions which by their nature involve the political process. The justification of solar programs is very weak - the fact that the President has set a goal of $20 \%$ can only be at best a secondary justification, and the desire to create a new industry is a very poor justification if there is no need for such an industry. To say that solar has not been guided by economic considerations would undermine a great deal of the DOE's activities. There is also no discussion of why the price mechanism has not, or is unlikely to, bring about the desired conservation measures and adoption of solar technology. 